Hickman, M. (1995) The Irish in Britain: racism. incorporation and identity. Irish Studies Review, 10, 16-20.

C. J. Haley Department of Clinical Psychology, The Whelan Building, Quadrangle, Brownlow Hill, Liverpool L69 3GB

Sir: Bracken et al's (1998) editorial was interesting but lacked scientific validity, for two reasons.

First, the authors failed to justify why being Irish-born constituted an 'ethnicity'. Ireland is a multi-ethnic English-speaking country made up largely of people from Celtic, Norse and Anglo-Saxon backgrounds. In this respect it does not differ substantially from any other part of the British Isles. I can see little validity in the claim that the Irish make up a more distinctive racial, linguistic, anthropological or cultural group than those of any other region within the UK or the Republic of Ireland do. The ethnicity of the White communities in Dublin and London probably bear more similarity than those of Newcastle and London. Nationality is not the same as ethnicity.

Second, it is not valid to compare the English health statistics of those born in Ireland with those born in England. A more valid comparison would be to compare Irish immigrants to those from Tyneside, Cornwall or South Wales who have migrated to other parts of the British Isles. I would suggest that migrated communities emanating from any of these poorer areas would share similarly poor mental health statistics. This would suggest that socioeconomic and migrational factors are of more importance than specifically 'ethnic' ones.

The underlying assumptions made by Bracken et al are that being Irish represents a distinct ethnicity, which suffers relatively poor mental health. They fail to justify either of these views.

Bracken, P. J., Greenslade, L., Griffin, B., et ol (1998) Mental health and ethnicity: an Irish dimension. British Journol of Psychiotry, 172, 103-105.

J. J. Sandford Fromeside Clinic, Blackberry Hill, Stapleton, Bristol BSI6 IED

Authors' reply We wholly agree with $\mathrm{Dr}$ Haley regarding the significance of gender when considering the mental health of Irish migrants in Britain. Irish women constitute an invisible minority within an invisible minority as far as mental health needs are concerned, although the literature on the experience of Irish women is less wellestablished than Dr Haley suggests. Our article was intended to highlight the neglect of Irish mental health needs in Britain as a whole and it was written in the hope that drawing attention to these needs might engender further research and intervention.

Dr Sandford's comments demand slightly more attention. His first assertion, that Irish migrants do not constitute a distinct ethnic and cultural minority within Britain, must be rejected. The fact is that they meet the principal criteria for defining such status as established by the Race Relations Act 1976 and subsequent judgements (Hickman \& Walter, 1997) and are recognised as an ethnic group by both the Commission for Racial Equality and numerous statutory bodies within Britain. Dr Sandford's position implies a crude reductionism conflating 'biological race' with culture and ethnicity. Perhaps his view might be different if Irish people had green skin.

Regarding the suggested comparison of Irish migrants with indigenous internal migrants, we can only remark that it is commonplace in migrant health research to compare the health status of migrant groups with that of the indigenous population as a whole (e.g. Balarajan, 1995). Certainly in studies of physical health and mortality this is accepted practice (e.g. Marmot et al, 1984). Internal migration might indeed have a bearing on mental health, but $\mathrm{Dr}$ Sandford's suggestion becomes meaningful only if we accept his first contention that Irish migrants do not constitute a distinct group within the British population as a whole. The question of socio-economic factors remains open since, to our knowledge, no research exists which might explicate matters in the case of mental health. Available research does not support Dr Sandford's view that migration or socioeconomic factors may be more significant than ethnic or cultural status in explaining the high excess mortality among the sertled children of Irish migrants (Raftery et al, 1990; Harding \& Balarajan, 1996).

Epidemiological research which has employed simple ethnic categorisations, such as White, Asian and African/Caribbean, has been successful in demonstrating differential health experiences among minorities in Britain. However, the major thrust of our paper is that such categorisations are not only simple, but simplistic, and tend to conceal as much as they reveal. There is a growing consensus among health researchers that the standard classification, based as it is on notions of racial difference, is inadequate and needs re-thinking. In two successive decades Irish-born people had the highest rates of psychiatric in-patient admission of any country-of-birth group within England and Wales, and among the highest rates of suicide and parasuicide. These findings have been almost wholly ignored by service providers and practitioners in psychiatry.

Balarajan, R. (1995) Ethnicity and variations in the nation's health. Heolth Trends, 27, 114-119.

Harding, S. Balarajan, R. (1996) Patterns of mortality in second generation Irish living in England and Wales: longitudinal study. British Medical Journal, 312. 1389-1392.

Hickman, M. J. \& Walter, B. (1997) Discriminotion and the lish Community in Britoin. London: Commission for Racial Equality.

Marmot, M. G., Adelstein, A. M. \& Bulman, L. (1984) Immigront Mortolity in England and Woles 1971 78. London: HMSO.

Raftery, J., Jones, D. R. \& Rosato, M. (1990) The mortality of first and second generation Irish immigrants in the UK. Sociol Science and Medicine, 31. 577-584.

P. J. Bracken Department of Social and Economic Studies, University of Bradford

L. Greenslade American College. Dublin B. Griffin Birmingham Irish Mental Health Forum, Ladywood. Birmingham

M. Smyth Northern Birmingham Mental Health Trust, Birmingham

\section{Risk of sudden death on high-dose antipsychotic medication: QTC dispersion}

Sir: Since the publication of the 'Consensus statement' on the use of high-dose antipsychotics (Thompson, 1994), psychiatrists have been performing electrocardiograms (ECGs) on their high-dose patients. The rationale behind this is that it will detect conduction abnormalities, especially QT prolongation, associated with an increased risk of sudden cardiac death. It is recognised that the risk of a conduction abnormality due to medication is doserelated and is greatest with phenothiazines. Although more common at higher doses, QTc prolongation (>440 ms) is found in patients on the full range of antipsychotic dosages (Warner et al, 1995). There is also evidence to suggest that patients can have 
drug-induced prolongation of QT intervals with little risk of arrhythmia (Day et al, 1990). This suggests that QTc prolongation in itself is not necessarily a good indicator of risk for sudden death.

QTc dispersion is an ECG-derived measure of the difference between the longest and the shortest QTc interval on the 12-lead ECG (Slyven et al, 1984). While a degree of variability between leads is normal, increased QTc dispersion is an indication of more extreme variability in ventricular repolarisation. Such extreme variability could be regarded as an index of the risk of arrhythmia. QTc dispersion is gaining recognition as a predictor of sudden cardiac death in conditions as varied as idiopathic long QT syndromes (JervellLange-Nielsen syndrome and RomanoWard syndrome), diabetes mellitus, peripheral vascular disease, congestive heart failure and coronary artery disease (Campbell, 1996). Measurements taken years beforehand correlate with a patient's risk of sudden death. Warner et al (1996) measured QT dispersion in their in-patient survey but could not find a significant association between larger QT dispersion and antipsychotic doses in excess of $2000 \mathrm{mg}$ chlorpromazine equivalent per day. (It should be noted that only 16 of their patients were in this group.) As sudden death is relatively infrequent in a population on high-dose antipsychotics, measurement of QTc dispersion may give a clearer indication of which patients are at greater risk than reliance on QTc prolongation alone.

Campbell, R. (1996) Commentary; QT dispersion may reflect vulnerability to ventricular fibrillation. British Medical journal, 312, 878-879.

Day, C. P., McComb, J. M. \& Campbell, R.W. F. (1990) QT dispersion: an indication of arrhythmia risk in patients with long QT intervals. British Heart Journal, 63, 342-344.

Slyven, J. C., Horacek, B. M., Spencer, C. A., et ol (1984) QT interval variability on the body surface. journol of Electrocardiology, 17, 179-188.

Thompson, C. (1994) The use of high-dose antipsychotic medication. British journol of Psychiotry. 164. $448-458$.

Warner, J. P., Barnes, T. R. E. \& Henry, J. A. (1996) Electrocardiographic changes in patients receiving neuroleptic medication. Acto Psychiatrica Scandinavica. 93. $311-313$.

J. M. Barber Department of Psychiatry, Southern General Hospital, 1345 Govan Road, Glasgow G5I 4TF

\section{Ethnicity and clozapine metabolism}

Sir: Chong \& Remington (1998) have pointed out the very important influence of ethnicity on clozapine metabolism. In a recently held National Psychiatric Conference in Pakistan, a number of psychiatrists suggested that in their clinical experience their patients responded to relatively smaller doses of clozapine. This may be due to the fact that our patients attain higher plasma levels at relatively lower doses, as suggested by Chang et al (1993) and Chong et al (1997). These findings have serious implications about side-effects such as seizures, drowsiness and weight gain, etc., which are dose-related. The cost factor is equally important as in most developing countries the patients and their families have to bear the cost. If these findings can be supported by more empirical data, a costly drug such as clozapine could be made available to a larger number of patients.

However, this problem cannot be addressed by comparative studies between various ethnic groups, as suggested by Chong \& Remington (1998). These studies are needed to highlight the differences pointed out by the authors, but the real need is to study the pharmacokinetics of a new drug in a particular population before recommending therapeutic doses or plasma levels in that population. It may prove very difficult, if not impossible, to get proper controls for such cross-ethnic studies in view both of differences in individual variables (e.g. body weight, height, etc.) inherent in various ethnic groups, and other extraneous factors (e.g. environmental temperature affecting body and drug metabolism). At present, dosages and plasma levels for monitoring drugs such as lithium are thought to be universally similar, mostly on the basis of data obtained in European and American populations. Professionals working in populations which have different biological parameters (which can affect drug metabolism differently) have a responsibility to ask the pharmaceutical industry to provide relevant information before experimenting with these drugs in human subjects.

Chang, W. H., Chein, C. P., Lin, S. K., et al (1993) Elevated clozapine concentrations in Chinese patients Neuropsychophormocology, 9,1175-1185

Chong, S. A. \& Remington, G. (1998) Ethnicity and clozapine metabolism (letter). British journal of Psychiotry, 172, 97.
—, Tan, C. H., Khoo, Y. H., et al (1997) Clinical evaluation and plasma clozapine concentrations in Chinese patients with schizophrenia. Theropeutic Drug Montoring. 19 219-223

S. Farooq Department of Psychiatry.

Postgraduate Medical Institute, Lady Reading

Hospital, Peshawar, Pakistan

\section{Comprehensiveness of systematic review}

Sir: Adams et al (1998) are right to take us to task for not describing our literature search parameters as clearly as we should (Lawrie \& Abukmeil, 1998), but are wrong to suggest that our search strategy would have missed a sizeable number of articles of considerable or direct interest.

For the record, we searched the October 1996 Silver Platter edition of Medline using the search terms 'MAGNETIC RESONANCE IMAGING/all subheadings' and 'SCHIZOPHRENIA/all subheadings'. Articles of potential interest were then examined for suitability. As we stated (Lawrie \& Abukmeil, 1998) those articles giving complete or near-complete raw volumes of one or more brain regions were included, while area studies and volumetric studies of the corpus callosum and basal ganglia were excluded as were a large number of irrelevant papers (see below). In other words, as we stated, " 40 relevant volumetric MRI studies were identified" not 40 studies in total. To demonstrate, a search on current Ovid software using our search strategy identified 333 potentially relevant studies published by June 1996, of which only 36 met inclusion criteria. The rest reported: areas (32), irrelevant volumes (22), findings in children (2) or the elderly (7), qualitative appearances (23), magnetic resonance spectroscopy (12), functional imaging (11), methodological issues (11), conference abstracts (10), uncontrolled studies/case reports (36), letters (22), review articles (51) and other matters (58).

It is far from clear that a more sophisticated search would be worth the extra effort. Adams et al allude to possible Medline publication bias through language, but our review included seven papers from German, Italian and Japanese research groups who had reported in English. It would, however, be interesting to establish whether a more elaborate search would identify more papers and perhaps even alter the results of our review for a pre-specified 